\title{
Tsafon
}

Revue d'études juives du Nord

$81 \mid 2021$

Des synagogues à travers les âges Lieux de prières, lieux d'études et autres fonctions

\section{Lévy-Garber Ode, Passé sous silence}

\section{Danielle Delmaire}

\section{(2) OpenEdition \\ 1 Journals}

\section{Édition électronique}

URL : https://journals.openedition.org/tsafon/4020

DOI : $10.4000 /$ tsafon. 4020

ISSN : 2609-6420

Éditeur

Association Jean-Marie Delmaire

\section{Édition imprimée}

Date de publication : 1 juillet 2021

Pagination : 161-162

ISSN : $1149-6630$

\section{Référence électronique}

Danielle Delmaire, «Lévy-Garber Ode, Passé sous silence », Tsafon [En ligne], 81 | 2021, mis en ligne le 01 juillet 2021, consulté le 15 septembre 2021. URL : http://journals.openedition.org/tsafon/4020 ; DOI : https://doi.org/10.4000/tsafon.4020

Ce document a été généré automatiquement le 15 septembre 2021.

Tsafon. Revues d'études juives du Nord 


\title{
Lévy-Garber Ode, Passé sous silence
}

\author{
Danielle Delmaire
}

\section{RÉFÉRENCE}

Lévy-Garber Ode, Passé sous silence, réédition des entretiens d'Ode Lévy-Garber réalisés par Jean-Paul Woodall (bruits du temps) en 2015, version augmentée en documents et annexes, Nice, octobre 2020, 248 p., prix non indiqué.

1 L'équivoque du titre, selon que le mot " passé » est compris comme participe ou comme substantif, persiste après la lecture. En effet, faut-il comprendre que le récit a été peu entendu donc est passé (participe) sous silence ou bien que la difficulté de parler après la guerre a occasionné un silence et ce passé (substantif) surgit bien tardivement ? Peu importe car finalement les deux options peuvent accompagner la lecture du récit et la découverte du passé.

Odette Lévy, épouse Garber, est née en 1931, après quatre autres enfants, dans une famille juive originaire de l'Empire ottoman. C'est avant la Première Guerre mondiale que la famille de son père quitte un pays où l'antisémitisme et l'insécurité sont menaçants, pour divers pays : la Palestine ottomane, le Brésil et la France. Le couple s'est installé à Lille où la vie s'écoule sans encombre jusqu'au décès de la maman en 1938. Joseph Lévy se trouve veuf, jeune encore - il a un plus de quarante ans - avec quatre enfants adolescents et la petite dernière qui a tout juste sept ans.

3 À la déclaration de la guerre, le père emmène toute sa famille vers le sud avec l'espoir de gagner rapidement l'Espagne et de s'embarquer pour le Brésil où un frère pourrait l'accueillir. La tentative échoue et en 1940 un nouvel exode les amène à Saint-Gaudens. La jeune Odette y mène une vie pas trop mouvementée même si l'inquiétude taraude son père. Ses souvenirs sont plutôt plaisants. La famille reste à Saint-Gaudens jusqu'à la fin de 1942.

4 Après ces deux années, les nuages se font plus denses et, pour s'être déclarée, il devient plus prudent pour la famille de se réfugier dans un petit village non loin de Cahors: Arcambal. Odette se fait de nouveaux amis et fréquente l'école. Joseph, le père, parvient 
à travailler tandis que les sœurs ainées se débrouillent pour gagner quelque argent et entretenir la maison. Les rapports avec les habitants du village sont tout à fait cordiaux et pour Odette la vie est heureuse malgré les privations. Elle est trop jeune encore pour comprendre le sens des visites d'inconnus : son père Joseph et son frère Maurice âgé de 18 ans en 1944 participent à la résistance locale. La maison devient un lieu que l'on pense sûr pour cacher des armes, des documents compromettants et pour des rencontres secrètes.

arrive le 2 juillet 1944 lorsqu'une perquisition met à jour toutes ces activités illicites et dangereuses. En l'absence de Violette, les trois sœurs, Esther, Judith et Odette sont arrêtées. Joseph et Maurice sont emmenés pour interrogatoire : Maurice est horriblement torturé et finalement fusillé tandis que son père disparaît sans que ses filles parviennent à retrouver sa trace après la guerre.

Originaires de Turquie, pays allié au Reich, les trois sœurs sont déportées à Ravensbrück par le convoi 81, parti de Toulouse le 30 juillet 1944, alors que la ville est libérée une vingtaine de jours plus tard. Odette, âgée de 13 ans, connaît les affres de la déportation mais la présence de ses sœurs la soutient et la rassure. Elle est évacuée à Bergen-Belsen où son témoignage est très proche du récit de Lili Leignel : la faim, la peur, les maladies, l'absence de toute hygiène. Nous y lisons la même souffrance physique et morale et l'enfant qui ne comprend pas ce basculement dans l'horreur.

7 L'après n'est pas un retour au bonheur. Les sœurs ne parlent pas du drame d'Arcambal et encore moins de la déportation. C'est Violette, alors qu'elle a échappé à l'arrestation, qui surmonte le plus difficilement le traumatisme de la disparition du père et du frère. Longtemps Odette n'a pas voulu s'exprimer : la parole n'était pas une libération car elle ravivait la douleur. Le mutisme devenait protecteur. Toutefois, pas indéfiniment puisque dans les années 2010, devenue octogénaire, elle confie ses souvenirs à JeanPaul Woodall. Des redondances parsèment le récit mais ne perturbent pas la lecture car il est évident qu'Odette doit se répéter pour s'imprégner de ses souvenirs et pour convaincre le lecteur.

Outre le témoignage sur ce que fut la déportation à Ravensbrück et Bergen-Belsen, il faut retenir de cette lecture l'engagement résistant, fréquent chez les juifs réfugiés dans le sud de la France, des proscrits du régime. Ces juifs ne se sont pas résignés : ils ont combattu et n'ont pas trahi, même sous la torture. Ils se sont sacrifiés pour un pays qu'ils admiraient et ils ont refusé l'humiliation. C'est cela aussi et surtout cela que contient le témoignage d'Odette Lévy-Garber.

Le livre est enrichi par de nombreuses photos et documents, notamment les lettres et imprimés révélant les démarches longues et difficiles entreprises par Joseph Lévy pour obtenir la nationalité française, dans les années 1932-1933. La France, qu'il affectionnait tant, tergiversait pour l'intégrer avant de refuser de l'accepter parmi ses citoyens. Mais Joseph avait compris qu'il existait une autre France avec laquelle et pour laquelle il a combattu. 